DIE VERSTÄDTERUNG DER OPER 
ANSELM GERHARD

\section{DIE VERSTÄDTERUNG DER OPER}

Paris und das Musiktheater des 19. Jahrhunderts

Verlag J.B.Metzler Stuttgart · Weimar 
Die Deutsche Bibliothek - CIP-Einheitsaufnahme

\section{Gerhard, Anselm:}

Die Verstädterung der Oper : Paris und das Musiktheater des 19. Jahrhunderts / Anselm Gerhard. - Stuttgart : Metzler, 1992 ISBN 978-3-476-00850-3

\section{ISBN 978-3-476-00850-3 \\ ISBN 978-3-476-03424-3 (eBook) \\ DOI 10.1007/978-3-476-03424-3}

Dieses Werk einschließlich aller seiner Teile ist urheberrechtlich geschützt. Jede Verwertung außerhalb der engen Grenzen des Urheberrechtsgesetzes ist ohne Zustimmung des Verlages unzulässig und strafbar. Das gilt insbesondere für Vervielfältigungen, Übersetzungen, Mikroverfilmungen und die Einspeicherung und Verarbeitung in elektronischen Systemen.

(C) 1992 Springer-Verlag GmbH Deutschland

Ursprünglich erschienen bei J.B. Metzlersche Verlagsbuchhandlung und Carl Ernst Poeschel Verlag GmbH in Stuttgart 1992 


\title{
Inhaltsverzeichnis
}

\author{
Einleitung
}

Seite 1

"Grand Opéra« 1 . Großstadterfahrung und Rezeptionsgeschichte 3 Konventionen und Gattungsgeschichte 7 . Kaleidoskop und Widerspiegelungstheorie 11

\section{Realitäten einer Großstadt}

Seite 16

Zeittafel 16 . Realitäten einer Großstadt 22 . Theater - Ort der Träume 26 . Opern für ein neues Publikum 29 . Das Unternehmen Opéra 36 - Künstler als Kapitalisten 39

\section{Victor-Joseph Étienne de Jouy, Eremit inmitten der Großstadt}

Seite 43

"L'Hermite de la Chaussée d'Antin« 43 - Verzauberung der Sinne 44 Kontraste $51 \cdot$ Spiegel 55

\section{Rossini und die Revolution}

Seite 61

Le Siège de Corinthe 61 . Guillaume Tell 63 • "Une véritable révolution" 65 - Geschichten aus der Geschichte 68 - Das schaurige Ende 73 - Die Emanzipation des Chors 78 - "Die Erstgebohrnen der Freiheit" 85 "Quel tableau!« 87 . Der schwankende Held 93 - Der Rückzug der Prinzessin 97 - Melancholie 102 . Schweigen 105 


\section{Eugène Scribe, ein "unpolitischer« Literat}

Seite 111

La Muette de Portici 111 . Ein "unpolitischer" Literat 113 . Oper und Revolution 115 . "La pièce bien faite 122 . Das melodramatische Prinzip 127 · Pantomime 130 - Panorama 136

\section{Meyerbeer und das »juste milieu«}

Seite 142

Les Huguenots 142 - Kolorit 145 . Charakter 152 . Die gehorsame Tochter 158 . Der flüchtige Augenblick 162 . Schock 174 · Musik im Raum 180 - "juste milieu « 184

\section{Victor Hugo, der Dichterfürst als Librettist}

Seite 190

La Esméralda 190 . Vergleich zweier Dramaturgien 192 . Die Stadt in der Oper 195 . Angst vor den Massen 200 . Voyeurismus 204. Die Macht der Fatalität 210

\section{Meyerbeer und die Reaktion}

Seite 217

Le Prophète 217 . Pamphlet 220 . Traumbilder 228 . Erinnerung 236 Mutterliebe 245 - Demagogie 250 . Selbstmord 256 - Feuerzauber 262 Mosaik 268

\section{Der Komponist als Librettist}

Seite 281

Das Martyrium der Librettisten 281 . "La parola scenica« 287 . Der Traum von der Personalunion 290 . Libretti aus dem Fundus 296

\section{Verdi und die Krise der Institutionen}

Seite 303

Les Vêpres Siciliennes 303 - "Die gewohnten Mirakel« 305 - "Tête-àtête« 309 - Beschwörung 316 - Der ohnmächtige Vater 319 . Spleen 323 Abschied 329 . Zerfall 332 


\section{Zwischen den Nationen}

Seite 343

Nationalismus und Kosmopolitismus 343 - Mythos 350 - Das Modell "Grand Opéra" 357

\section{Verdi und das Intérieur}

Seite 363

Un ballo in maschera 363 - "Osservazioni profonde“ $365 \cdot$ Konzision 373 Maskerade 379 . Der Chor als Kulisse 389 . Sehnsucht nach dem Intérieur 394 - Schrecken 400 - Vergangenheit und Zukunft 406

\section{Nachbemerkung und Dank}

Seite 410

\section{Anmerkungen}

Seite 412

\section{Literaturverzeichnis}

Seite 446

\section{Register}

Seite 481

Titel dramatischer Werke 481 . Personen 486 
On a toujours beaucoup écrit sur l'Opéra, on écrira toujours beaucoup, et il restera toujours beaucoup à écrire.

(Charles de Boigne, Petits Mémoires de l'Opéra) 